\title{
Evaluasi Pengelolaan Lansekap Areal Vila Obyek Wisata Bagus Agro Pelaga, Kabupaten Badung
}

\author{
I MADE SUARJAYA DWI SAPUTRA ${ }^{1}$, A.A. GEDE SUGIANTHARA ${ }^{1 *}$, \\ KOMANG ARTHAWA LILA ${ }^{1}$
}

1Program Studi Agroekoteknologi, Fakultas Pertanian, Universitas Udayana, JIn. PB. Sudiman, Denpasar 80362 Bali

*E-mail: seriramputrabali@gmail.com

\section{ABSTRACT \\ Evaluation of the Management Landscape in Bagus Agro Pelaga Vila Area, Badung Regency}

Landscape management it is really needen in the progress of Bagus Agro Pelaga (BAP) to improve tourism industry. The best landscape management and suistinable be able give more valve into development agrotourism and satisfaction to the guest. Landscape management is focused in this study only landscape management villa area. Purpose from this reseach is to know the consept of manage the landscape villa area which is used at BAP, know as technical orientation in managed landscape villa area in BAP, to analyst stemulation factor and brominated factor which is influence managerial activity landscape villa area in BAP. Reseach result indicate that planing most important program on the concept which is applied BAP for that villa mentioned already $80 \%$ appropriate. That is, what wash already planning appropriate with first purpose or first design. Base which is be orientation for landscape villa area in BAP is blend with concept terracing garden also management system which is democratic. The factor which is influence management landscape activity in BAP that is from internal factor such us, the necessity of SOP, increasing employee specially aesthetics employee on the villa area BAP, and the equitment isn't enough. External faktor review input from the visitor and obserb on location suck as, amount of plants, structuring and treatment of the plants, the occurrence of vandalism, cleanliness of the pool, not enough of garbage bin, garden bench, ganden lamp, and long chair.

Keywords : park management, park maintenance

\section{Pendahuluan}

Kawasan pedesaan merupakan tempat yang sangat strategis untuk objek wisata. Sebagian besar daerah pedesaan masih terlihat alami dengan pemandangan alam yang indah dan asri. Potensi ini mestinya mampu dimanfaatkan dan dioptimalkan oleh masyarakat setempat. Salah satunya dengan pengembangan agrowisata.

Salah satu agrowisata yang terdapat di Provinsi Bali adalah Bagus Agro Pelaga (BAP) yang terletak di Desa Pelaga, Kec. Petang, Kab. Badung. BAP merupakan 
kerjasama antara PT. (Persero) pengembangan pariwisata Bali (BTDC) memiliki lahan pertanian seluas $17,5 \mathrm{Ha}$ di Desa Pelaga dan PT. Puri Bagus Citra Lestari yang berpengalaman dalam bidang pariwisata dan agribisnis. Pengembangan BAP sebagai obyek wisata agro bertujuan untuk memanfaatkan seoptimal mungkin potensi yang ada di daerah Pelaga. Pemandangan alam yang indah dapat menjadi daya tarik untuk dikembangkannya obyek wisata agro, Budaya agraris dengan kearifan lokal masyarakat setempat, serta lokasi yang berada di antara dua daerah wisata terkenal Kintamani dan Bedugul menambah keberagaman dalam menunjang pengembangan pariwisata berbasis pertanian. Sebagai salah satu obyek wisata baru, BAP dilengkapi dengan berbagai fasilitas akomodasi untuk menunjang kenyamanan pengunjung di antaranya restoran, saung, wantilan, coffee roosting, aula, green house, vila, joging track, dan outborn. (PT. Bagus Agro Pelaga 2008).

Salah satu fasilitas yang dinilai sangat penting keberadaannya di BAP adalah fasilitas vila. Berdasarkan observasi lapangan, saat ini pengelolaan vila lebih banyak menonjolkan segi estetika, sehingga fungsi-fungsi lain seperti kebersihan, penataan taman, kondisi tanaman, kondisi hardscape, kenyamanan, dan keamanan belum diperhatikan. Fasilitas penunjang lansekap areal vila BAP jaga perlu diperhatikan seperti lampu taman yang tidak berfungsi sebagaimana mestinya, demikian pula bangku taman, tempat sampah, dan long chair pada kolam renang. Penataan lansekap di masing-masing vila tidak merata, hanya difokuskan di sudut-sudut tertentu.

Pengelolaan lansekap sangat diperlukan dalam pengembangan BAP khususnya areal vila untuk meningkatkan daya tarik agrowisata. Pengelolaan ini dapat meningkatkan minat wisatawan untuk berkunjung serta menjaga keberlangsungan BAP itu sendiri. Pengelolaan lansekap yang baik dan berkelanjutan dapat memberikan nilai tambah dalam pengembangan agrowisata dan kepuasan tersendiri bagi wisatawan. Oleh karena itu penulis tertarik untuk meneliti bagaimana pengelolaan lansekap areal vila yang diterapkan pihak pengelola BAP.

\subsection{Rumusan Masalah}

Berdasarkan dari latar belakang di atas maka permasalahan yang dapat diangkat dalam penelitian ini adalah:

1. Bagaimana konsep pengelolaan lansekap di areal vila yang diterapkan pihak pengelola BAP?

2. Bagaimana pedoman teknis dalam pengelolaan lansekap areal vila di BAP.

3. Apa saja faktor-faktor pendorong dan penghambat kegiatan pengelolaan lansekap areal vila di BAP?

\subsection{Tujuan Penelitian}

Dari permasalahan di atas, adapun tujuan yang ingin dicapai dalam penelitian ini adalah sebagai berikut :

1. Untuk mengetahui konsep pengelolaan lansekap areal vila yang diterapkan BAP.

2. Untuk mengetahui pedoman teknis dalam pengelolaan lansekap areal vila di BAP.

3. Untuk menganalisis faktor-faktor pendorong dan penghambat yang mempengaruhi kegiatan pengelolaan lansekap areal vila di BAP.

\subsection{Manfaat Penelitian}

Manfaat yang diharapkan dari penelitian ini adalah :

1. Mengetahui konsep pengelolaan dan pemeliharaan lansekap areal vila yang diterapkan BAP.

2. Menemukan pedoman teknis pengelolaan lansekap areal vila di BAP. 
3. Dapat merumuskan pemecahan masalah pengelolaan dan pemeliharaan yang menjadi faktor penghambat yang dihadapi BAP.

4. Menambah pengetahuan, ketrampilan, dan pengalaman kerja lapangan.

\subsection{Ruang Lingkup Penelitian}

Penelitian ini dilakukan di BAP, dengan ruang lingkup mengevaluasi pengelolaan lansekap areal vila. Pengelolaan lansekap yang di maksud adalah melakukan pemantauan dan menganalisis proses pengelolaan mulai dari perencanaan, konsep, pelaksanaan, pemeliharaan, serta pengawasan dan evaluasi yang dilakukan di kawasan wisata BAP. Data yang dibutuhkan berupa data primer dan sekunder. Data primer pada penelitian ini diperoleh dari wawancara internal Manager dan karyawan BAP, obsevasi lapangan, serta persepsi pengunjung. Data sekunder diperoleh dari hasil studi kepustakaan, baik melalui literatur yang ada, jurnal, makalah ilmiah, dan yang bersumber dari internet. Data yang diperoleh dianalisis, dan kemudian disajikan secara deskriptif sebagai output penelitian.

\section{Metode}

\subsection{Waktu dan Lokasi Penelitian}

Penelitian ini dilakukan di Bagus Agro Pelaga tepatnya, di Desa Pelaga, Kecamatan Petang, Kabupaten Badung, Provinsi Bali dengan ketinggian $750 \mathrm{~m}$ dpl (meter dari permukaan laut) pada bulan Oktober sampai dengan Desember 2014.

\subsection{Bahan dan Alat}

Penelitian ini memerlukan beberapa bahan dan alat antara lain, titik-titik pengamatan pada lokasi penelitian yang nantinya akan di teliti tepatnya pada ke empat areal vila dan satu lobi di BAP, dan peta dasar areal vila BAP. Alat yang digunakan yaitu, kamera digital untuk dokumentasi di lapangan, kuisioner, form observasi, alat tulis, perangkat komputer untuk mengolah data.

\subsection{Metode Pengumpula Data}

Metode yang digunakan dalam penelitian ini adalah metode survei dalam bentuk penelitian yang bersifat deskriptif. Tujuan dari penelitian deskriptif ini adalah untuk mendapat gambaran secara sistematis dan akurat mengenai fakta-fakta yang ada dalam pengelolaan lansekap areal vila BAP.

\subsection{Teknik Pengumpulan Data}

\section{Observasi Lapangan}

Observasi lapangan dilakukan dengan cara mengamati dan mencatat secara sistematik gejala-gejala yang diselidiki. Data yang diperoleh dari hasil observasi lapangan di BAP khususnya pada areal vila yaitu tentang kondisi tapak vila BAP yang terdiri dari elemen hardscape dan softscape.

\section{Kuesioner (angket)}

Kuesioner (angket) merupakan daftar pertanyaan yang telah dipersiapkan sebelumnya untuk mendapatkan data yang belum diperoleh dari hasil observasi dan wawancara. Data yang diperoleh dari kuesioner yaitu tentang penilaian pengunjung terhadap pengelolaan lansekap areal vila BAP.

\section{Wawancara}

Wawancara yang digunakan menggunakan wawancara terstruktur. Wawancara terstruktur adalah wawancara dengan menggunakan daftar pertanyaan yang telah disiapkan sebelumnya. Data yang diperoleh dari wawancara yaitu tentang gambaran umum vila BAP, operasional pengelolaan lansekap vila BAP yang terdiri dari pemeliharaan, serta monitoring dan evaluasi. 


\subsection{Teknik Analisis}

Skala pengukuran variabel yang digunakan dalam penelitian ini adalah mengacu pada Skala Likert (Lekert Scale). Sugiyono (1997) mengemukakan bahwa Skala Likert merupakan skala pengukuran yang diberikan pembobotan secara gradasi dari nilai yang positif hingga negatif. Skala Likert digunakan untuk mengukur sikap, pendapat dan persepsi sekumpulan atau seseorang tentang fenomena sosial yang selanjutnya disebut sebagai variabel penelitian. Selanjutnya Singarimbun (1994) menambahkan, setiap jawaban yang dihubungkan dengan bentuk pernyataan atau dukungan sikap yang diungkapkan dengan kata-kata sebagai berikut :

1. Jawaban Sangat Baik diberi skor 100.

2. Jawaban Baik diberi skor 80.

3. Jawaban Cukup diberi skor 60 .

4. Jawaban Buruk diberi skor 40.

5. Jawaban Sangat Buruk diberi skor 20.

Dalam mengklasifikasikan dan membantu interpretasi hasil penelitian, maka digunakan Skala Likert yang dapat dilihat pada Tabel 1. Nilai interval kelas diperoleh dengan rumus :

$$
\begin{gathered}
I=\frac{\text { Skor Tertinggi-Skor Terendah }}{\text { Jumlah Kelas }} \\
I=\frac{100-20}{5} \\
I=\frac{80}{5}=16
\end{gathered}
$$

Nilai rata-rata yang dihasilkan dari perhitungan akan dikonfersikan oleh Tabel 1 sehingga dapat diklasifikasikan pada suatu katagori persepsi.

Tabel 1. Skala Likert Skala Persepsi Wisatawan

\begin{tabular}{cllcc}
\hline No & & Persepsi & Skor & Interval kelas(\%) \\
\hline 1 & Sangat Baik & 100 & $>84 \%-100 \%$ \\
2 & Baik & 80 & $>68 \%-84 \%$ \\
3 & Cukup & 60 & $>52 \%-68 \%$ \\
4 & Buruk & 40 & $>36 \%-52 \%$ \\
5 & Sangat Buruk & 20 & $20 \%-36 \%$ \\
\hline
\end{tabular}

Teknik pengolahan data yang digunakan dalam mengolah hasil kuesioner pengelolaan lansekap dalam penelitian ini adalah teknik tabulasi data dalam bentuk persentase (\%). Tabulasi data merupakan langkah memasukkan data berdasarkan hasil pengumpulan data di lapangan. Teknik tabulasi data dalam bentuk persentase $(P)$ digunakan untuk menghitung jumlah pilihan responden $(\mathrm{N})$ ke dalam bentuk persentase (\%) (Warsito, 1992). Perhitungan persentase ini menggunakan rumus yaitu :

$$
P=\frac{F}{N} \times 100 \%
$$

Keterangan :

$P=$ Persentase

$\mathrm{F}=$ Frekuensi

$\mathrm{N}=\Sigma$ Total Responden 


\section{Hasil dan Pembahasan}

\subsection{Gambaran Umum Villa Bagus Agro Pelaga}

Vila merupakan salah satu fasilitas penunjang di BAP yang dinilai sangat penting keberadaannya. BAP saat ini memiliki empat vila dan satu lobi yang terletak di sebelah timur kantor pengelolaan dengan luas kurang lebih 0,2 Ha. Letak dari vila ini sendiri sudah diperhitungkan dengan sangat matang. Ada beberapa faktor yang menjadi dasar dibangunnya vila di areal tersebut, salah satunya karena tempat tersebut di nilai merupakan tempat yang paling strategis untuk pembangunan vila, hal ini dapat dilihat dari view yang bagus, pencahayaan atau sinar matahari yang baik. (Wawancara Internal Manager BAP, 2014).

Mengenai RTH (Ruang Terbuka Hijau), dalam vila BAP sudah sesuai dengan peraturan yang berlaku yaitu menyisakan RTH minimal 20\% dari luas lahan atau areal yang ada (UU No 26 Tahun 2007, dalam Ulupi, 2013). Konsep taman yang villa BAP mengangkat tema taman terasering yang didominasi oleh tanaman berproduksi. Konsep penataan taman/lansekap yang diterapkan di vila BAP mengangkat tema taman/lansekap terasering yang didominasi oleh tanaman holtikultura buah-buahan seperti nanas, nangka, alpukat, jambu biji, jeruk besar, pepaya. Konsep ini bertujuan agar nantinya taman/lansekap terasering di vila BAP tidak hanya bisa dinikmati dari segi keindahan namun, juga dapat dimanfaatkan untuk konsumsi. Landasan yang dijadikan pedoman pada lansekap areal vila BAP yaitu pola lansekap campuran dengan sistem pengelolaan yang demokratis. Konsep yang diterapkan BAP pada vila tersebut sudah $80 \%$ sesuai artinya, apa yang direncakan hampir seluruhnya terlaksana sesuai dengan tujuan awal atau desain awal. Terdapat empat program kerja yang saat ini dilaksanakan oleh pihak estetika khususnya areal vila yaitu, terdapat tiga program kerja jangka pendek dan satu program kerja jangka panjang. Program kerja jangka pendek antara lain, pemeliharaan taman secara rutin, Perbaikan taman bagian utara dari vila, serta renovasi atap bangunan vila dan lobi. Program kerja jangka panjang antara lain, panataan taman pada vila baru yang akan dilaksanakan pada tahun 2015. Semua program kerja di atas tiga di antaranya sudah terlaksana dan satu program jangka panjang yang tersisa karena menunggu pembuatan enam unit vila baru. (Wawancara Internal Asisten Manager BAP, 2014).

\subsection{Kondisi Tapak villa Bagus Agro Pelaga}

Elemen yang terdapat di vila BAP terbagi atas hardscape dan softscape. Berdasarkan hasil pengamatan dilapangan elemen hardscape adalah fasilitas yang tersedia di vila BAP dapat dilihat pada Tabel 2 sedangkan softscape merupakan vegetasi yang terdapat di vila BAP dapat dilihat pada Tabel 3.

Tabel 2. Daftar Hardscape di Vila BAP

\begin{tabular}{ccccc}
\hline No & Elemen & Jumlah & Kondisi & Ket \\
\hline 1 & Bangunan Vila & 4 unit & Baik & \\
2 & Jalan Setapak & $800 \mathrm{~m}^{2}$ & Baik & \\
3 & Candi & 1 Buah & Baik & \\
4 & Kolam Renang & 1 Buah & Kurang Baik & \\
5 & Lampu Taman & 28 Buah & Kurang Baik & \\
6 & Pot Tanaman & 15 Buah & Baik & \\
7 & Patung & 3 Buah & Baik \\
8 & Tempat Sampah & 1 Buah & Baik \\
9 & Toilet & 4 Unit & Baik & \\
10 & Lobi & 1 Unit & Baik \\
\hline
\end{tabular}


Elemen hardscape pada Tabel 2 di atas merupakan elemen yang terdapat di areal vila BAP yang terdiri dari jumlah dan kondisi yang berbeda-beda. Terutama yang purlu diperhatikan adalah pada elemen kolam renang, dan lampu taman yang kondisinya kurang baik. Kolam renang di areal vila BAP perlu debersihkan secara rutin agar, kebersihan kolam tetap terjaga dan material kolam tidak cepat mengalami kerusakan. Kondisi yang sama juga terjadi pada elemen lampu taman yang belum terpelihara dengan baik dan tidak berfungsi sebagai mana mestinya. Berdasarkan observasi dilapangan dua elemen yang kondisinya kurang baik disebabkan karena Kurangnya perhatian dari pihak pengelola terkait khususnya bidang estetika, dan jumlah karyawan estetika yang ditempatkan di areal vila kurang memadai yaitu hanya dua orang karyawan. Tindakan lainnya yang harus diperhatikan lagi adalah jumlah tempat sampah yang belum memadai, long chair atau tempat bersantai di kolam renang yang belum ada, bangku taman yang perlu di tambahkan sebagai fasilitas penunjang, dan pemeliharaan elemen lain harus ditingkatkan kembali. (Observasi Lapangan 2014)

Tabel 3. Daftar Nama Tanaman yang Ada di Vila BAP

\begin{tabular}{|c|c|c|c|c|c|c|}
\hline No & Nama Indonesia & Nama Latin & $\begin{array}{c}\text { Nama Lokal } \\
\text { (Bali) }\end{array}$ & Jenis Tanaman & Kondisi & Jumlah \\
\hline 1 & Puring & Codiaeum variegatum & - & Perdu & Baik & 162 Pohon \\
\hline 2 & Nangka & Artocarpus heterophyllus & Nangka & Pohon & Baik & 4 Pohon \\
\hline 3 & Alpukat & Persea americana & Pokat & Pohon & Baik & 1 pohon \\
\hline 4 & Cempaka & Michelia campaka & Cempaka & Pohon & Baik & 1 Pohon \\
\hline 5 & Jeruk Besar (Pamelo) & Citrus grandis, C. maxima & - & Pohon & Baik & 5 Pohon \\
\hline 6 & Kamboja Merah & Plumeria rubra & Jepun Barak & Perdu & Baik & 2 Pohon \\
\hline 7 & Kamboja Kuning & Plumeria acutifolia & Jepun Kuning & Perdu & Baik & 2 Pohon \\
\hline 8 & Jambu Biji & Psidium guajava & Nyambu & Pohon & Baik & 3 Pohon \\
\hline 9 & Nanas & Ananas comosus & Manas & Semak & Baik & 10 Pohon \\
\hline 10 & Rumput Gajah Mini & Pennisetum purpureum & - & Penutup Tanah & Baik & $800 \mathrm{~m}^{2}$ \\
\hline 11 & Palem putri & Chrysadilocarpus lutescens & Peji & Perdu & Baik & 2 Pohon \\
\hline 12 & Teratai & Nymphaea sp. & Tunjung & Semak & Baik & 6 Pohon \\
\hline 13 & Pucuk Merah & Oleina Syzygium & - & Perdu & Baik & 6 Pohon \\
\hline 14 & Herbras & Garbera $L$ & - & Perdu & Baik & 37 Pohon \\
\hline 15 & Kaktus & Euphorbia lactea & - & Perdu & Kurang Biak & 5 Pohon \\
\hline 16 & Kacang Piring & Gadenia jasminoides & - & Perdu & Baik & 6 Pohon \\
\hline 17 & Kacang Piring/Gardinia & Gardenia jasminoides & - & Perdu & Baik & 2 Pohon \\
\hline 18 & Pepaya & Carica papaya & Gedang & Pohon & Kurang Baik & 1 Pohon \\
\hline 19 & Pakis Tanduk Rusa & Platycrum bifurcatum & Simbar Menjangan & Semak & Baik & 9 Pohon \\
\hline 20 & Kembang Sepatu & Hibiscus rosa-sinensis & Pucuk & Perdu & Baik & 1 Pohon \\
\hline 21 & Mahoni & Swietenia mahagoni & Mahoni & Pohon & Baik & 2 Pohon \\
\hline 22 & Andong Merah & Cordyline fruticosa & Andong Barak & Semak & Baik & 171 Pohon \\
\hline 23 & Lidah Mertua & Sansevieria trafasciata & - & Semak & Baik & 105 Pohon \\
\hline 24 & Alamanda & Allamanda oenotheraefolia & - & Semak & Baik & 7 Pohon \\
\hline 25 & Kupea Putih & Cuphoa hyssopifolia "Alba" & - & Semak & Kurang Baik & 123 Pohon \\
\hline 26 & Iris Liar Kuning & Dietes bicolor & - & Semak & Baik & 155 Pohon \\
\hline 27 & Heliconia Nuri Jingga & Heliconia rostrata & - & Perdu & Baik & 134 Pohon \\
\hline 28 & Leli Kaki Bebek & Hymenocalis latifolia & - & Semak & Baik & 50 Pohon \\
\hline 29 & Pandan Daun Lebar & Pandanus dubius & Pandan & Perdu & Baik & 2 Pohon \\
\hline 30 & Ekor Kucing & Acalypha hispida & - & Perdu & Baik & 1 Pohon \\
\hline
\end{tabular}

Vegetasi pada Tabel 3 di atas merupakan elemen softscape yang terdapat di areal vila BAP. Beberapa hal yang perlu diperhatikan diantaranya, jumlah tanaman khususnya tanaman holtikultura perlu ditambah kembali untuk mempertegas konsep taman atau 
desain awal. Kemudian penataan dan perawatan tanaman yang perlu ditingkatkan lagi, dan mengurangi terjadinya vandalism (Observasi Lapangan 2014).

\subsection{Operasional pengelolaan lansekap di vila BAP}

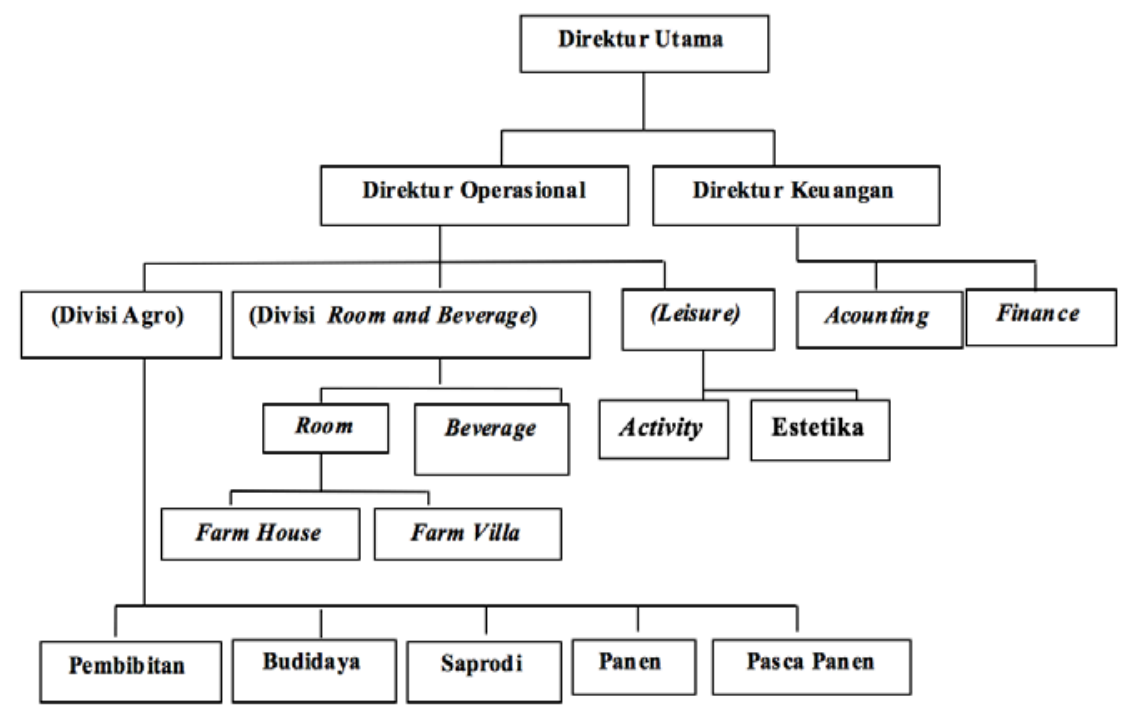

Gambar 1. Struktur Organisasi BAP

Berdasarkan struktur organisasi BAP, operasional pengelolaan lansekap berada di bawah pengawasan Direktur Operasional pada Divisi Leisure (Gambar 1). Pengelolaan lansekap areal vila BAP terdiri dari pemeliharaan, serta monitoring dan evaluasi.

\subsubsection{Pemeliharaan}

Kegiatan pemeliharaan taman di vila BAP meliputi pemeliharaan hardscape, pemeliharaan softscape. Untuk mengetahui efektifitas kerja dalam kegiatan pemeliharaan dilakukan penghitungan kapasitas kerja dengan menggunakan rumus menurut Arifin dan Arifin (2005).

$$
\text { Kapasitas Kerja }(\mathrm{KK})=\frac{\text { Luas Lahan }}{\text { Waktu } \times \text { Jumlah Pekerja }}
$$

Menurut Arifin dan Arifin (2005), kapasitas kerja adalah besarnya kemampuan tenaga kerja untuk melakukan suatu pekerjaan dalam waktu satu jam. Kapasitas kerja dipengaruhi oleh luas lahan, desain, jenis pekerjaan, kelengkapan alat, dan pengawasan. Kapasitas kerja pemeliharaan taman dihitung berdasarkan luas lahan per satuan hari orang kerja (HOK) yang merupakan kemampuan orang mengerjakan satu jenis pekerjaan dalam satu hari kerja yaitu selama delapan (8) jam kerja dengan luasan tertentu.

Tabel 4 menunjukkan bahwa hanya jenis pekerjaan pemangkasan yang sesuai dengan kapasitas kerja yang ditentukan. Sedangkan menyapu, dan memupuk sudah melebihi kapasitas yang ditentukan oleh Arifin. Kemudian penyiraman, proteksi HPT, dan penyiangan dilakukan sewaktu-waktu. Sesuai dengan klasifikasi iklim menurut SchmidFerguson (BMKG, 2013) tipe iklim kawasan Kecamatan Petang termasuk dalam tipe iklim A yaitu sangat basah dengan perbandingan 11 bulan basah dan 1 bulan kering oleh sebab itu penyiraman dilakukan jika memang sangat dibutuhkan. pengendalian HPT dilakukan dengan cara manual mencabut tanaman yang terserang hama/penyakit kemudian menggantinya dengan tanaman baru. Penyiangan dilakukan setiap hari. 
Tabel 4. Kapasitas Kerja Pemeliharaan Taman Vila BAP dan Standar Kapasitas Kerja Pemeliharaan Taman

\begin{tabular}{|c|c|c|c|c|c|c|c|c|}
\hline No & $\begin{array}{c}\text { Jenis } \\
\text { Pekerjaan } \\
\text { Taman }\end{array}$ & $\begin{array}{c}\text { Jumlah } \\
\text { Karyawan } \\
\text { Taman }\end{array}$ & $\begin{array}{l}\text { Luas } \\
\text { Areal } \\
\left(\mathrm{m}^{2}\right)\end{array}$ & $\begin{array}{l}\text { Waktu } \\
\text { (Jam) }\end{array}$ & $\begin{array}{c}\text { Kapasitas } \\
\text { Kerja(1) } \\
\text { (m²/Jam) }\end{array}$ & $\begin{array}{c}\text { Kapasitas } \\
\text { Kerja(2) } \\
\text { (m²/Jam) }\end{array}$ & $\begin{array}{l}\text { Frekuensi } \\
\text { Pemeliharaan } \\
\text { Musim } \\
\text { Kemarau }\end{array}$ & $\begin{array}{c}\text { Frekuensi } \\
\text { Pemeliharaan } \\
\text { Musim Hujan }\end{array}$ \\
\hline 1 & Menyapu & 2 & $2.000 \mathrm{~m}^{2}$ & 1 & 1.000 & 800 & Setiap Hari & Setiap Hari \\
\hline 2 & Menyiram & Insidentil & - & - & - & - & Insidentil & Insidentil \\
\hline 3 & Memupuk & 2 & $2.000 \mathrm{~m}^{2}$ & 1 & 1.000 & 200 & 1 Bulan 1 Kali & 1 Bulan 2 Kali \\
\hline 4 & Pemangkasan & 2 & $2.000 \mathrm{~m}^{2}$ & 4 & 250 & 250 & 1 Bulan 1 Kali & 1 Bulan 2 Kali \\
\hline 5 & Proteksi HPT & Insidentil & - & - & - & - & Insidentil & Insidentil \\
\hline 6 & Penyiangan & 2 & $2.000 \mathrm{~m}^{2}$ & 6 & 166,6 & 40 & 1 Bulan 1 Kali & 1 Bulan 3 Kali \\
\hline 7 & Penyulaman & Insidentil & - & - & - & - & Insidentil & Insidentil \\
\hline 8 & $\begin{array}{l}\text { Pemeliharaan } \\
\text { Hardscape }\end{array}$ & Insidentil & - & . & - & - & Insidentil & Insidentil \\
\hline
\end{tabular}

Sumber: Wawancara 2014

Keterangan: (1): Pengamatan Lapang di Vila BAP

(2): Kapasitas Kerja Pemeliharaan Taman (Arifin dan Arifin, 2005)

\subsubsection{Monitoring dan Evaluasi Pengelolaan lansekap vila BAP}

Pengelolaan vila BAP dapat dinilai dari dua hal yaitu internal dan eksternal. Pengelolaan internal dapat dilihat dari pihak management estetika dan karyawan. Dari ke dua pihak tersebut dapat dilihat bagaimana kondisi pengelolaan vila di BAP dari faktor internal. Di bawah ini adalah Tabel pengawasan dan evaluasi yang dilakukan oleh Management estetika BAP.

Tabel 5. Pengawasan dan Evaluasi Management Estetika BAP

\begin{tabular}{|c|c|c|c|c|}
\hline No & Spesifikasi & Ya & Tidak & Keterangan \\
\hline 1 & $\begin{array}{l}\text { Monitoring Lapangan dilakukan/ } \\
\text { SetiapHari/SetiapMinggu/ Bulanan/ Tahunan }\end{array}$ & $\sqrt{ }$ & & Setiap Hari \\
\hline 2 & $\begin{array}{l}\text { Evaluasi dilakukan/Setiap Hari/ Setiap Minggu/ } \\
\text { Bulanan/ Tahunan }\end{array}$ & $\sqrt{ }$ & & Setiap Minggu \\
\hline 3 & Pelaksanaan sesuai rencana & $\sqrt{ }$ & & \\
\hline 4 & Membuat SOP & & $\sqrt{ }$ & - \\
\hline 5 & Struktur Organisasi & $\sqrt{ }$ & & \\
\hline
\end{tabular}

Berdasarkan tabel di atas ada satu hal penting yang tidak ada dalam pengelolaan lansekap di vila BAP yaitu adalah standar operasional prosedur (SOP). SOP pemeliharaan taman merupakan sebuah panduan yang digunakan untuk menjalankan pemeliharaan taman. Berdasarkan pengamatan yang dilakukan di BAP ternyata dalam perencanaan awal tidak dibuat SOP pemeliharaan sehingga karyawan hanya bekerja sesuai perintah yang diberikan oleh pihak managemant estetika. Berdasarkan pengamatan dilapangan selain pengawasan dan evaluasi pengelola juga menyediakan sarana prasarana penunjang lansekap yang dibutuhkan untuk keberlangsungan pengelolaan taman. Adapun sarana prasarana penunjang yang ada di BAP dapat dilihat pada Tabel 6.

Selain fator - faktor internal diatas mulai dari monitoring, evaluasi, ada faktor internal lainnya yang berpengaruh terhadap kondisi pengelolaan vila di BAP yaitu karyawan kususnya bidang estetika. Kurangnya karyawan estetika secara keseluruhan maupun di areal vila kususnya, menjadi salah satu kendala yang dihadapi dalam pengelolaan lansekap areal vila di BAP. Tindakan lainnya yang harus di perhatikan lagi adalah jumlah alat kerja yang masing kurang memadai. 
Tabel 6. Sarana Prasarana Penunjang Lansekap di BAP

\begin{tabular}{cccccc}
\hline No & \multicolumn{1}{c}{ Spesifikasi } & Ada & Tidak & Jumlah & Keterangan \\
\hline 1 & Tempat pembibitan & $\sqrt{ }$ & & 1 & \\
2 & Tempat pembuatan pupuk & $\sqrt{ }$ & & 1 & \\
3 & Alat-alat kerja : & & & & \\
& $>$ Cangkul & $\sqrt{ }$ & & 1 & \\
& $>$ Pemotong Rumput & $\sqrt{ }$ & & 1 & \\
& $>$ Gunting Rumput & $\sqrt{ }$ & $\sqrt{ }$ & & \\
4 & Penggunaan bahan kimia & & & & \\
\hline
\end{tabular}

\subsection{Penilaian Pengunjung Terhadap Pengelolaan Lansekap Areal Vila BAP}

Penilaian pengunjung ini diperoleh dengan menyebarkan kuesioner kepada 30 orang pengunjung secara acak. Persepsi pengunjung ini merupakan perbandingan, dan juga masukan dari pengelolaan internal lansekap areal vila di BAP yang nantinya diharapkan dapat bermanfaat terhadap keberlangsungan lansekap areal vila di BAP. Berdasarkan persentase penilaian pengunjung untuk masing-masing zona diperoleh; zona welcome areal $73 \%$, zona areal vila $71 \%$, zona areal kolam renang $67 \%$. Maka jika di lihat rata-rata persentase pengelolaan dari ke tiga zona berdasarkan skala likert dapat digolongkan baik (70\%). Namun, masih banyak yang perlu dibenahi pada lansekap areal vila BAP terutama di zona areal kolam renang yang masuk dalam katagori cukup.

Tabel 7. Pengelolaan Lansekap Areal Vila BAP

\begin{tabular}{|c|c|c|}
\hline \multicolumn{3}{|c|}{ Zona Welcome Areal } \\
\hline 1 & 2 & 3 \\
\hline No & Aspek & Nilai \\
\hline 1 & Estetika (Keindahan) & $74 \%$ \\
\hline 2 & Kebersihan & $73 \%$ \\
\hline 3 & Penataan Taman & $76 \%$ \\
\hline 4 & Kondisi Tanaman & $71 \%$ \\
\hline 5 & Kondisi Hardscape & $69 \%$ \\
\hline 6 & Kenyamanan & $76 \%$ \\
\hline \multicolumn{3}{|c|}{ Persentase Pengelolaan : 73\% } \\
\hline \multicolumn{3}{|c|}{ Zona Areal Vila } \\
\hline No & Aspek & Nilai \\
\hline 1 & Estetika (Keindahan) & $77 \%$ \\
\hline 2 & Kebersihan & $68 \%$ \\
\hline 3 & Penataan Taman & $75 \%$ \\
\hline 4 & Kondisi Tanaman & $68 \%$ \\
\hline 5 & Kondisi Hardscape & $69 \%$ \\
\hline 6 & Kenyamanan & $73 \%$ \\
\hline 7 & Fasilitas & $69 \%$ \\
\hline \multirow{2}{*}{\multicolumn{3}{|c|}{$\begin{array}{l}\text { Persentase Pengelolaan : } 71 \% \\
\text { Zona Areal Kolam Renang }\end{array}$}} \\
\hline & & \\
\hline No & Aspek & Nilai \\
\hline 1 & Estetika (Keindahan) & $70 \%$ \\
\hline 2 & Kebersihan & $63 \%$ \\
\hline 3 & Penataan Taman & $67 \%$ \\
\hline 4 & Kondisi Tanaman & $70 \%$ \\
\hline 5 & Kondisi Hardscape & $67 \%$ \\
\hline 6 & Kenyamanan & $63 \%$ \\
\hline 7 & Fasilitas & $65 \%$ \\
\hline 8 & Keamanan & $67 \%$ \\
\hline \multicolumn{3}{|c|}{ Persentase Pengelolaan : $67 \%$} \\
\hline \multicolumn{3}{|c|}{ Rata-rata Persentase Pengelolaan : $70 \%$} \\
\hline
\end{tabular}

Sumber : Kuesioner pengunjung, 2014 
'Faktor-faktor penyebab kurangnya penilaian pengunjung di zona ini disebabkan oleh kurangnya fasilitas penunjang seperti long chair, ornamen patung pada kolam renang yang tidak berfungsi sebagaimana mestinya, keamanan, kondisi hardscape yang kurang terjaga, penataan taman, dan kebersihan. Tindakan lain yang harus diperhatikan pada ketiga zona adalah penambahan jumlah tanaman, vandalisme, peningkatan penataan dan perawatan tanaman kembali, penambahan fasilitas penunjang seperti tempat sampah, bangku taman yang masih kurang, dan pemulihan fungsi lampu taman sebagaimana mestinya. Selera taman yang diinginkan pengunjung lansekap areal vila di BAP dijelaskan pada tabel 8.

Tabel 8. Selera Taman yang diinginkan oleh Pengunjung

\begin{tabular}{ccccc}
\hline No & Spesifikasi & $\begin{array}{c}\text { Kondisi } \\
\text { (P1, P2, Smk, Pt) } \\
\text { Dibiarkan Alami }\end{array}$ & $\begin{array}{c}\text { Kondisi } \\
\text { (P1, P2, Smk,Pt) } \\
\text { Dipangkas teratur } \\
\text { dan rapi }\end{array}$ & $\begin{array}{c}\text { Kondisi } \\
\text { (P1, P2, Smk, Pt) Ada } \\
\text { yang alami dan ada } \\
\text { yang di pangkas }\end{array}$ \\
\hline $\mathbf{1}$ & Taman welcome areal & $33,3 \%$ & $30 \%$ & $36,7 \%$ \\
$\mathbf{2}$ & Taman areal vila & $30 \%$ & $26,7 \%$ & $43,3 \%$ \\
$\mathbf{3}$ & Taman areal kolam renang & $16,7 \%$ & $40 \%$ & $43,3 \%$ \\
\hline \multicolumn{2}{l}{ (Sumber: Koesioner Pengunjung 2014). }
\end{tabular}

Keterangan: P1 :Pohon, P2 :Perdu, Smk : Semak, Pt : Penutup Tanah

\section{Simpulan}

\subsection{Simpulan}

Berdasarkan hasil penelitian dapat ditarik simpulan sebagai berikut:

1. Perencanaan program terutama pada konsep yang diterapkan BAP pada vila tersebut sudah $80 \%$ sesuai.

2. Landasan yang dijadikan pedoman pada lansekap areal vila BAP adalah lansekap campuran dengan konsep taman terasering.

3. Faktor-faktor yang menpengaruhi kegiatan pengelolaan lansekap BAP yaitu, tidak adanya SOP sebagai panduan atau acuan bagi semua karyawan dalam menjalankan tugas masing-masing.

4. Kurangnya tenaga kerja khusunya karyawan estetika di areal vila BAP, dan jumlah alat kerja yang masih belum memadai.

5. Berdasarkan hasil evaluasi responden terhadap kepuasan pengunjung, pengelolaan lansekap areal vila tergolong baik terutama pada zona welcome area dan zona areal vila, sedangkan untuk zona areal kolam renang termasuk dalam katagori cukup.

6. Berdasarkan masukan-masukan pengunjung dan observasi lapangan ada beberapa hal yang perlu diperhatikan di antaranya, jumlah tanaman, penataan dan perawatan tanaman, terjadinya vandalisme, kebersihan kolam renang, kurangnya fasilitas penunjang seperti tempat sampah, bangku taman, lampu taman, dan long chair.

\subsection{Saran}

Berdasarkan hasil penelitian, maka dapat diajukan saran sebagai berikut:

1. Perlu dibuatkan SOP pengelolaan taman yang menjadi panduan atau acuan bagi semua karyawan dalam menjalankan tugas masing-masing.

2. Pihak pengelola hendaknya menambah karyawan estetika dan memberi mereka training sebelum mempekerjakannya.

3. Pihak pengelola hendaknya menambah alat-alat kerja yang dibutuhkan oleh karyawan estetika, untuk mendukung kinerja para karyawan. 


\section{Daftar Pustaka}

Arifin, H.S dan N.H.S. Arifin. 2005. Pemeliharaan Taman. Penebar Swadaya. Jakarta. BMKG, 2013. Peran BMKG Dalam Antisipasi Bencana Kekeringan. Badan Meteorologi Klimatologi dan Geofisika Wilayah III Denpasar.

PT. Bagus Agro Pelaga, 2008. Rencana Kerja dan Anggaran Perusahaan. PT. Bagus Agro Pelaga. Badung.

Singarimbun, Masri. 1994. Metode Penelitian Survai. LP3ES. Jakarta.

Sogiyono, 1997. Untuk Penelitian. Alfabeta. Bandung.

Ulupi, R. A. 2013. Pengelolaan Lansekap Budaya Kertalangu Kec. Denpasar Timur, Kota Denpasar, Provinsi Bali. Skripsi. Fakultas Pertanian Universitas Udayana. Denpasar.

Warsito, Hermawan. 1992. Pengantar Metodelogi Penelitian. Gramedia Pustaka Utama. Jakarta. 